\title{
Enhancement of innate immunity by curcuminoids and hormones as a therapeutic strategy in neurodegenerative disorders
}

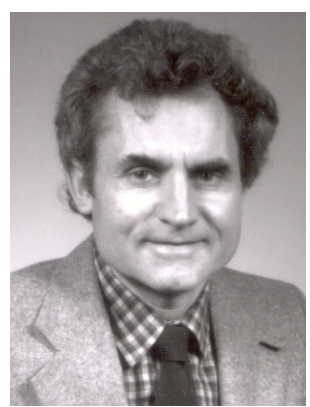

Milan Fiala

Greater LA VA Medical Center \& UCLA School of Medicine, Department of Medicine, 73-084 CHS, UCLA, 650 Charles E Young Drive South, Los Angeles, CA 90095, USA

Tel.: + 13102066392

Fax: +13108252042 fiala@mednet.ucla.edu future, part of fso $\therefore$...adaptive and innate immunity components need to work in

unison. Future therapies will need to pay attention to improving both innate and adaptive immunity.'

Despite impressive advances in the understanding of the neuropathological basis of Alzheimer's disease $(\mathrm{AD})$ as being related to neuronal toxicity of amyloid- $\beta$ (A $\beta ; 1-40$ and $1-42)$ in fibrillar, soluble or oligomeric form according to the amyloid hypothesis [1], there is as yet no clinically successful strategy to remove $A \beta$ deposits from the brain. In sporadic cases of $\mathrm{AD}$, amyloidosis of the brain may be related to defective clearance of $A \beta$ [2]. Several groups have shown diligent interest in microglial clearance of $A \beta[3,4]$, leading to the development of an $A \beta$ vaccine [5] and a clinical trial, which was, however, abrogated due to adverse encephalitic complications [6]. On the other hand, microglia, with the help of complement and astrocytes, have been shown to be a perpetrator of inflammatory damage in neurodegenerative diseases $[7,8]$, and anti-inflammatory therapies with different nonsteroidal anti-inflammatory drugs have had a continuing vogue [9]. The role of microglia in $A \beta$ clearance was initially proposed as being due to Fc-receptor-mediated phagocytosis and $A \beta$ degradation by microglia [4]. Another strategy for $A \beta$ clearance purports that antibodies can dissolve $A \beta$ deposits [10] and immunoglobulin administration may have beneficial effects in $\mathrm{AD}$ patients [11]. In a third scenario, peripherally administered anti-A $\beta$ antibody creates a sink that drains $A \beta$ from the brain [12]. In this editorial we will present our proposals on new strategies for $A \beta$ brain clearance by natural substances to bolster the innate immune system. According to our hypothesis, the normal innate immune system, with the help of adaptive immunity, should be able to clear $A \beta$ from the brain unless there is overproduction of $A \beta$. We must advise the general readership that the concepts presented below are not yet in the mainstream but are receiving further support from our ongoing studies and those of other investigators.
The first issue is the identity of the innate immune cells responsible for $A \beta$ clearance. Traditionally, activated microglia are considered to be responsible for both brain inflammation and $A \beta$ phagocytosis $[13,14]$ through various receptors, including the class B scavenger receptor [15]. Our immunohistochemical studies of AD brain demonstrated that inducible nitric oxide-synthase-positive and cyclooxygenase-2-positive bloodborne monocytes/macrophages penetrate across brain microvessels (with destruction of interendothelial zonula occludes-1 protein) and significantly infiltrate perivascular and parenchymal sites, but only partially clear neuritic plaques [16-18]. These observations suggested that, in addition to microglia, in the human brain with $\mathrm{AD}$, peripheral monocytes/macrophages are the cells involved in $A \beta$ clearance. Our neuropathological results received recent support from studies in animal models of AD. Two groups have demonstrated the ability of peripheral blood macrophages and $\mathrm{T}$ cells to invade the brain of aged amyloid-precursor protein transgenic mice [19] and to clear $A \beta$ deposits [20]. We also noted that the density of macrophage infiltration of neuritic plaques was not (inversely) related to residual $A \beta$ (as would be expected if $A D$ macrophages could efficiently clear $A \beta$ ) and speculated that the cardinal problem in $\mathrm{AD}$ lies specifically in the dysfunction of macrophages. Our studies of over 100 patients and approximately 40 control subjects are revealing unsuspected pathophysiology of $\mathrm{AD}$ monocyte/macrophages, which is probably not explained by serum factors since they are noted even in the presence of fetal bovine serum. We are detecting heterogeneous defects in macrophage differentiation in vitro, $A \beta$ uptake and trafficking to lysosomes, and apoptosis on exposure to $A \beta$. In addition, patients' monocytes overexpress interleukin-12 and patients' CD4 $\mathrm{T}$ cells overproduce interleukin-10 and interferon- $\gamma$, the cytokines belonging to both $\mathrm{T}$ helper (Th) 1 and Th2 sets. Thus, the adaptive and innate immune system components of $\mathrm{AD}$ patients seem to be in various stages of disharmony and dysfunction. In stark contrast, macrophages of control subjects voraciously ingest $\mathrm{A} \beta$ and appear to degrade it (probably without the 
help of antibodies) [17]. In conclusion, we believe that the whole innate immune system (including macrophages and microglia) in $\mathrm{AD}$ patients may be defective and its pathological state can be evaluated by studying peripheral blood monocyte/macrophages.

\section{$\therefore$...there is as yet no clinically successful strategy to remove $A \beta$ deposits from the brain.'}

The second issue is the classical controversy between the benefits of therapeutic strategies targeting inflammation versus $A \beta$ removal by the immune system. This subject has recently been elegantly reviewed from the point of view of transgenic animal models, with the conclusion that inflammation may induce both beneficial $\mathrm{A} \beta$ phagocytic responses and adverse neurotoxic responses [21]. However, the problem is that although current transgenic animals do model brain amyloidosis, albeit iatrogenically, they do not reproduce the immune problem of patients with AD. Therefore, we have been studying the benefits of enhancing immune responses to $A \beta$ using peripheral blood leukocytes of patients and control subjects.

Following the demonstration of defective phagocytosis of $A \beta$ by macrophages of a majority of $\mathrm{AD}$ patients [17], we have investigated the substances previously shown to be effective in clearance of $A \beta$ plaques in transgenic animals, that is to say curcuminoids [22] and insulin-like growth factor [23]. In cultured macrophages of $\mathrm{AD}$ patients in vitro, curcuminoids improved the defect in macrophage phagocytosis of $A \beta$ in $50 \%$ of patients in a small study [24]. The responding patients were younger and had higher minimental scores, suggesting that patients in the less advanced stages of AD may respond better. This mechanism of action of curcuminoids is novel and seemingly not in line with the anti-inflammatory and proapoptotic effects of curcuminoids. However, the multitude of regulatory effects of curcuminoids on cell-signaling pathways lends credence to the concept that curcuminoids may be returning the cell to a physiological balance [25]. In addition, we have observed that treatment of $\mathrm{AD}$ macrophages with insulin-like growth factor improved $A \beta$ phagocytosis in some macrophages, but we have not yet determined whether hormonal and curcuminoid effects are synergistic or additive. It is tantalizing to speculate whether the effects of immunomodulating and anti-inflammatory therapies could be evaluated in vitro and individualized according to each subject's innate and adaptive immune responses.

\section{'...the whole innate immune system ... in \\ AD patients may be defective and its pathological state can be evaluated by studying peripheral blood monocyte/macrophages.'}

In addition to our novel approaches, classical immunological approaches have been proposed to mitigate the encephalitic problem. Microglia have been activated with beneficial and adverse effects using lipopolysaccharide [26] or a proteosome-based adjuvant (Protolin ${ }^{\circledR}$ ) [27]. A strong consideration has been given to the possibility that a Th1-cell response against $A \beta$ was responsible for encephalitis in vaccinated subjects and, therefore, strategies to circumvent this complication have been designed using mucosal immunization or using only the B-cell epitope of $A \beta$ for vaccination [28]. In all of these approaches, the adaptive and innate immunity components need to work in unison. Future therapies will need to pay attention to improving both the innate and adaptive immunity.

\section{Bibliography}

1. Hardy J, Selkoe DJ: The amyloid hypothesis of Alzheimer's disease: progress and problems on the road to therapeutics. Science 297(5580), 353-356 (2002).

2. Bell RD, Sagare AP, Friedman AE et al.: Transport pathways for clearance of human Alzheimer's amyloid $\beta$-peptide and apolipoproteins $\mathrm{E}$ and $\mathrm{J}$ in the mouse central nervous system. J. Cereb. Blood Flow Metab. DOI: 10.1038/ sj.jcbfm.9600419 (2007) (Epub ahead of print).
3. Rogers J, Lue LF: Microglial

chemotaxis, activation, and phagocytosis

of amyloid $\beta$-peptide as linked

phenomena in Alzheimer's disease.

Neurochem. Int. 39(5-6), 333-340

(2001).

4. Bard F, Cannon C, Barbour R et al: Peripherally administered antibodies against amyloid $\beta$-peptide enter the central nervous system and reduce pathology in a mouse model of Alzheimer disease. Nat. Med. 6(8), 916-919 (2000).
5. Schenk D, Barbour R, Dunn W et al: Immunization with amyloid- $\beta$ attenuates Alzheimer-disease-like pathology in the PDAPP mouse (see comments). Nature 400(6740), 173-177 (1999).

6. Monsonego A, Weiner HL: Immunotherapeutic approaches to Alzheimer's disease. Science 302(5646), 834-838 (2003).

7. McGeer EG, McGeer PL: The importance of inflammatory mechanisms in Alzheimer disease. Exp. Gerontol. 33(5), 371-378 (1998). 
8. Akiyama H, Barger S, Barnum S et al.: Inflammation and Alzheimer's disease. Neurobiol. Aging 21(3), 383-421 (2000).

9. McGeer PL, Rogers J, McGeer EG: Inflammation, anti-inflammatory agents and Alzheimer disease: the last 12 years. J. Alzheimers Dis. 9(Suppl. 3), S271-S276 (2006).

10. Frenkel D, Dori M, Solomon B: Generation of anti- $\beta$-amyloid antibodies via phage display technology. Vaccine 22(19), 2505-2508 (2004).

11. Istrin G, Bosis E, Solomon B: Intravenous immunoglobulin enhances the clearance of fibrillar amyloid- $\beta$ peptide. J. Neurosci. Res. 84(2), 434-443 (2006).

12. DeMattos RB, Bales KR, Cummins DJ, Dodart JC, Paul SM, Holtzman DM: Peripheral anti-A $\beta$ antibody alters $\mathrm{CNS}$ and plasma $\mathrm{A} \beta$ clearance and decreases brain $A \beta$ burden in a mouse model of Alzheimer's disease. Proc. Natl Acad. Sci. USA 98(15), 8850-8855 (2001).

13. McGeer PL, McGeer EG: Inflammation, autotoxicity and Alzheimer's disease. Neurobiol. Aging 22(6), 799-809 (2001).

14. Bacskai BJ, Kajdasz ST, Christie RH et al.: Imaging of amyloid- $\beta$ deposits in brains of living mice permits direct observation of clearance of plaques with immunotherapy. Nat. Med. 7(3), 369-372 (2001).

15. El Khoury JB, Moore KJ, Means TK et al: $\mathrm{CD} 36$ mediates the innate host response to $\beta$-amyloid. J. Exp. Med. 197(12), 1657-1666 (2003).
16. Fiala M, Liu NQ, Reddy S, Graves M: Macrophages infiltrate the brain and express COX-2 and iNOS in Alzheimer's disease and AIDS. Alzheimer's Reports 4(1), 1-7 (2001).

17. Fiala $\mathrm{M}$, Lin J, Ringman J et al.: Ineffective phagocytosis of amyloid- $\beta$ by macrophages of Alzheimer's disease patients. J. Alzheimers Dis. 7(3), 221-232 (2005).

18. Fiala M, Liu QN, Sayre J et al.: Cyclooxygenase-2-positive macrophages infiltrate the Alzheimer's disease brain and damage the blood-brain barrier. Eur. J. Clin. Invest. 32(5), 360-371 (2002).

19. Stalder AK, Ermini F, Bondolfi L et al:: Invasion of hematopoietic cells into the brain of amyloid precursor protein transgenic mice. J. Neurosci. 25(48), 11125-11132 (2005).

20. Simard AR, Soulet D, Gowing G, Julien JP, Rivest $\mathrm{S}$ : Bone marrow-derived microglia play a critical role in restricting senile plaque formation in Alzheimer's disease. Neuron 49(4), 489-502 (2006).

21. Wyss-Coray T: Inflammation in Alzheimer disease: driving force, bystander or beneficial response? Nat. Med. 12(9), 1005-1015 (2006).

22. Yang F, Lim GP, Begum AN et al:: Curcumin inhibits formation of amyloid $\beta$ oligomers and fibrils, binds plaques, and reduces amyloid in vivo. J. Biol. Chem. 280(7), 5892-5901 (2005).

23. Carro E, Trejo JL, Gomez-Isla T, LeRoith D, Torres-Aleman I: Serum insulin-like growth factor I regulates brain amyloid- $\beta$ levels. Nat. Med. 8(12), 1390-1397 (2002).
24. Zhang L, Fiala M, Cashman J et al: Curcuminoids enhance amyloid- $\beta$ uptake by macrophages of Alzheimer's disease patients. J. Alzheimers Dis. 10, 1-7 (2006).

25. Shishodia S, Sethi G, Aggarwal BB: Curcumin: getting back to the roots. Ann. NY Acad. Sci. 1056, 206-217 (2005).

26. Quinn J, Montine T, Morrow J, Woodward WR, Kulhanek D, Eckenstein F: Inflammation and cerebral amyloidosis are disconnected in an animal model of Alzheimer's disease. J. Neuroimmunol. 137(1-2), 32-41 (2003).

27. Frenkel D, Maron R, Burt DS, Weiner HL: Nasal vaccination with a proteosome-based adjuvant and glatiramer acetate clears $\beta$-amyloid in a mouse model of Alzheimer disease. J. Clin. Invest. 115(9), 2423-2433 (2005).

28. Weiner HL, Frenkel D: Immunology and immunotherapy of Alzheimer's disease. Nat. Rev. Immunol. 6(5), 404-416 (2006).

\section{Affiliation}

\section{- Milan Fiala, $M D$}

Greater LA VA Medical Center \& UCLA School of Medicine, Department of Medicine, 73-084 CHS, UCLA, 650 Charles E Young Drive South, Los Angeles, CA 90095, USA Tel.: + 13102066392 Fax: +1310825 2042, fiala@mednet.ucla.edu 